\title{
FORMULASI NANOEMULSI DARI KOMBINASI EKSTRAK BUNGA MAWAR (Rosa damascena Mill) DAN EKSTRAK BENGKOANG (Pachyrhizus erosus) DENGAN PEMBAWA MINYAK Medium Chain Tryglicerides (MCT Oil)
}

\author{
Gina Ardian*, Hajrah, Adam M Ramadhan \\ Laboratorium Penelitian dan Pengembangan Kefarmasian "Farmaka Tropis", \\ Fakultas Farmasi, Universitas Mulawarman, Samarinda, Indonesia \\ *Email: ginaardian.ga@gmail.com
}

\begin{abstract}
These roses and Bengkoang are used by rural communities in the East Kalimantan region as a basic ingredient for the treatment of acne scars. Roses and Bengkoang have flavonoid compounds that work as antioxidants. MCT oil as a nanoemulsion solvent which can dissolve drugs or compounds that have low solubility in water. This study aims to determine nanoemulsion formula with MCT oil carrier and physical characteristics of nanoemulsion. In making nanoemulsion using the sonication method with 3 main components namely oil carrier, surfactant and cosurfactant. The materials used in nanoemulsion are ethanol, cremophor RH 40 and tween 80, with various comparisons. The results of the study obtained formulas with a comparison of MCT oil: Tween80: Ethanol (1: 6: 1) with a pH value of 4.1, particle size 67.86nm, Polidispersibility Index 0.561
\end{abstract}

Keywords : Rosa damascena Mill, Pachyrhizus erosus, MCT oil, nanoemulsion.

\begin{abstract}
ABSTRAK
Bunga mawar dan bengkoang ini sering digunakan oleh masyarakat pedalaman di daerah Kalimantan Timur sebagai bahan dasar untuk perawatan bekas jerawat. Bunga mawar dan bengkoang memiliki senyawa golongan flavonoid yang berfungsi sebagai antioksidan. MCT oil sebagai pelarut nanoemulsi yang dapat melarutkan obat atau senyawa yang memiliki kelarutan rendah dalam air. Penelitian ini bertujuan untuk mengetahui formula nanoemulsi dengan pembawa minyak MCT oil dan karakteristik fisik dari sediaan nanoemulsi. Pada pembuatan nanoemulsi menggunakan metode sonikasi dengan 3 komponen utama yaitu pembawa minyak, surfaktan dan kosurfaktan. Bahan yang digunakan dalam nanoemulsi yaitu etanol, cremophor RH 40 dan tween 80, dengan berbagai perbandingan. Hasil penelitian diperoleh formula dengan perbandingan MCT oil: Tween80: Etanol (1: $6: 1)$ dengan nilai $\mathrm{pH} 4,1$, ukuran partikel 67.86nm, Indeks Polidispersibilitas 0,561 .
\end{abstract}

Kata kunci: Rosa damascena Mill, Pachyrhizus erosus, MCT oil, nanoemulsi.

DOI: https://doi.org/10.25026/mpc.v8i1.326 


\section{PENDAHULUAN}

Pemanfaatan bunga mawar dan bengkoang sebagai bahan dasar dalam pembuatan sediaan farmasi sudah banyak berkembang seiring bertambahnya waktu terutama pemanfaatannya dalam bidang kosmetik. Kombinasi dari bunga mawar dengan bengkoang pun telah digunakan oleh masyarakat pedalaman di daerah Kalimantan Timur sebagai bahan dasar perawatan wajah untuk menghilangkan bekas jerawat. Bunga mawar sendiri memiliki kandungan kimia yang cukup banyak diantaranya tannin, geraniol, nerol, citronellol, asam geranik, terpene, flavonoid, pektin polyphenol, vanillin, karotenoid, stearopten, farnesol, eugenol, feniletilakohol, vitamin $\mathrm{B}, \mathrm{C}, \mathrm{E}$, dan $\mathrm{K}$. Menurut Yulianingsih, dkk (2006) yang dikutip oleh Ribkahwati, minyak atsiri mawar yang diekstrak dari bahan mahkota bunga dapat menjaga kelembaban kulit dan membantu menyamarkan kerutan pada kulit ${ }^{[9]}$. Sedangkan Lukitaningsih dan Holzgrabe (2013) menyatakan bahwa bengkoang mengandung senyawa golongan isoflavon yaitu daidzein, daidzein-7-o- $\beta$ glukopiranosa, 5-OH-daidzein-7-o- $\beta$ glukopiranosa dan 8,9-furanylpterocarpan-3-ol ${ }^{[5]}$.

MCT oil banyak digunakan dalam produk makanan, obat maupun kosmetik karena sifatnya yang tidak menimbulkan iritasi. MCT oil pada umumnya digunakan sebagai pelarut dalam sediaan emulsi, mikroemulsi, maupun nanoemulsi yang dapat melarutkan obat atau senyawa yang memiliki kelarutan rendah dalam air $^{[7]}$. Kelebihan utama MCT oil adalah stabilitas oksidatifnya yang tinggi sehingga tidak menimbulkan ketengikan dan tahan terhadap pemanasan. Asam lemak dalam MCT oil lebih pendek daripada asam lemak pada $L C T$ sehingga $M C T$ oil mempunyai sifat fisik lebih polar sehingga lebih mudah larut dalam air ${ }^{[1]}$

Nanoemulsi adalah sistem emulsi yang transparan, tembus cahaya dan merupakan disperse minyak air yang distabilkan oleh lapisan film dari surfaktan, yang memiliki ukuran droplet $50 \mathrm{~nm}-500 \mathrm{~nm}^{[8]}$. Nanoemulsi telah diterapkan dalam berbagai industri farmasi, diantaranya yaitu untuk penghantar transdermal, bahan atau unsur yang potensial dalam beberapa produk perawatan tubuh, dan pembawa yang baik pada obat sehingga dapat meningkatkan bioavailabilitas obat dalam tubuh ${ }^{[4]}$. Keuntungan nanoemulsi antara lain adalah dapat melindungi obat yang sensitif, meningkatkan bioavailabilitas oral obat sehingga mengurangi dosis yang digunakan, dapat dengan mudah disimpan karena mempunyai sistem yang stabil secara termodinamika ${ }^{[6]}$.

\section{METODE PENELITIAN}

Alat

Alat yang digunakan terdiri atas Gelas kimia (Pyrex), Kaca arloji (Pyrex), Corong Pisah (Pyrex), Timbangan analitik (precisa), $\mathrm{pH}$ meter (Jenway), Hot plate dan stirrer (Stuart), Rotary evaporator (Buchi), Sonikator (Krisbow), Spektrofotometer UV-VIS.

Bahan

Bahan yang digunakan terdiri dari Ekstrak Bengkoang Bunga mawar Tween 80 (Merck), MCT oil (Merck), Aqua deion ( Merck), Etanol (Merck), Cremophor RH 40 (Merck), PEG 400 (Merck), DPPH (Merck).

\section{Pembuatan ekstrak Mawar dan ekstrak bengkoang}

Kelopak bunga mawar, dipotong kecil kecil, kemudian di maserasi dengan etanol 96\% lalu didiamkan selama 12 jam, setelah itu disaring dan dipisahkan antara filtrat dan ampas. Kemudian filtrat di rotary evaporator dengan suhu 50$60^{\circ} \mathrm{C}$. Sampel yang dikumpulkan lalu disortasi, dicuci bersih lalu dikeringkan. Umbi bengkoang diekstraksi dengan metode soxhletasi menggunakan pelarut 
petroleum eter, metanol, kemudian disaring dan ekstrak selanjutnya diperkatkan dengan rotary evaporator. Setelah diperoleh ekstrak metanol pekat, ditambahkan air lalu ekstrak dipartisi dengan etil asetat dan dihasilkan fraksi etil asetat umbi bengkoang.

\section{Pembuatan Nanoemulsi}

Disuspensikan ekstrak dalam fase minyak yaitu MCT oil, kemudian ditambahkan dengan kosurfaktan berupa etanol dan PEG 400 dengan perbandingan yang telah ditentukan. Terakhir ditambahkan surfaktan yaitu cremophor $R H 40$ dan tween 80 pada perbandingan yang telah ditentukan lalu diaduk dengan pengaduk magnetic (100 rpm, 45 menit). Lalu campuran ditempatkan dalam sonikator tipe bath selama 20 menit. Diaduk hingga terbentuk nanoemulsi dan dilakukan peegukuran persen transmittan, formula nanoemulsi dengan persen transmitan mendekati air yaitu $100 \%$ dilanjutkan untuk pengujian lain yaitu uji ukuran droplet, organoleptis, dan $\mathrm{pH}$.

\section{Pengujian Karakteristik Nanoemulsi Uji Organoleptis}

Pengamatan

organoleptis nanoemulsi dilakukan secara visual menggunakan pancaindera, parameter yang diamati meliputi warna, bau, kejernihan dan homogenitas.

Uji pH

Pengukuran pH $\begin{array}{r}\text { sediaan } \\ \text { dengan }\end{array}$
nanoemulsi dilakukan
menggunakan pH meter.

Tabel 1 Optimasi Formula

\begin{tabular}{ccccccccccccc}
\hline Komposisi & \multicolumn{11}{c}{ Formula } \\
\cline { 2 - 13 }$(\%$ b/b $)$ & F1 & F2 & F3 & F4 & F5 & F6 & F7 & F8 & F9 & F10 & F11 & F12 \\
\hline Ekstrak & X & X & x & x & X & x & X & X & X & X & x & X \\
MCT oil & 1 & 1 & 1 & 1 & 1 & 1 & 1 & 1 & 1 & 1 & 1 & 1 \\
Cremophor RH 40 & 7 & 8 & 7 & - & - & - & 7 & 8 & 6 & - & - & - \\
Tween 80 & - & - & - & 7 & 8 & 6 & - & - & - & 7 & 8 & 6 \\
Etanol & - & - & - & - & - & - & 2 & 1 & 1 & 2 & 1 & 1 \\
PEG 400 & 2 & 1 & 1 & 2 & 1 & 1 & - & - & - & - & - & - \\
Aqua deion ad & 5 & 5 & 5 & 5 & 5 & 5 & 5 & 5 & 5 & 5 & 5 & 5 \\
\hline
\end{tabular}

Tabel 2 Hasil evaluasi optimasi Formula

\begin{tabular}{ccccccccccccc}
\hline \multirow{2}{*}{ Evaluasi } & \multicolumn{10}{c}{ Formula } \\
\cline { 2 - 13 } & F1 & F2 & F3 & F4 & F5 & F6 & F7 & F8 & F9 & F10 & F11 & F12 \\
\hline $\mathrm{pH}$ & 5,7 & 6,3 & 6,5 & 4,8 & 4,8 & 4,7 & 6,1 & 5,5 & 5,5 & 4,1 & 4,5 & 4,1 \\
$\mathrm{~T}(\%)$ & 92 & 86 & 90,7 & 66 & 86,9 & 85 & 67 & 97,3 & 97,5 & 97,3 & 64 & 98,7 \\
\hline
\end{tabular}

Keterangan: $\mathrm{T}=$ Transmittan 


\section{Uji Persen Transmittan}

Larutan diukur persen transmitannya pada panjang gelombang $650 \mathrm{~nm}$ menggunakan spektrofotometri UV-Vis. Aqua deion digunakan sebagai blangko saat pengujian. Formulasi yang memiliki persentase transmitan 90\%$100 \%$ menunjukkan bahwa formulasi tersebut memiliki penampakan visual yang jernih dan transparan ${ }^{[4]}$.

\section{Uji Ukuran Partikel, Indeks polidispersibilitas. \\ Pengujian dilakukan dengan} menggunakan PSA (Particle Size Analyzer) dengan tipe Dynamic Light Scattering. Sebanyak $10 \mathrm{ml}$ sampel diambil dan dimasukkan ke dalam kuvet. Kuvet harus terlebih dahulu dibersihkan sehingga tidak mempengaruhi hasil analisis. Kuvet yang telah diisi dengan sampel kemudian dimasukkan ke dalam sampel holder dan dilakukan analisis oleh instrumen. Data yang diperoleh yaitu, ukuran partikel, nilai polidispersibilitas indeks polidispersibilitas yang mengindikasikan keseragaman ukuran droplet. Nilai polidispersibilitas yang rendah menunjukkan ukuran droplet yang seragam hasil telah sesuai dengan teori yang ada yaitu $<1$.

\section{HASIL DAN PEMBAHASAN}

Nanoemulsi adalah sistem emulsi yang transparan, tembus cahaya dan merupakan disperse minyak air yang distabilkan oleh lapisan film dari surfaktan, yang memiliki ukuran droplet $50 \mathrm{~nm}-500 \quad \mathrm{~nm}^{[8]}$. MCT oil pada umumnya digunakan sebagai pelarut dalam sediaan emulsi, mikroemulsi, maupun nanoemulsi yang dapat melarutkan obat atau senyawa yang memiliki kelarutan rendah dalam air ${ }^{[7] .}$

Dalam penelitian ini dilakukan pembuatan formula nanoemulsi dari kombinasi ekstrak bunga mawar dengan ekstrak bengkoang dengan pembawa minyak MCT oil, dengan berbagai perbandingan surfaktan dan kosurfaktan.
Sebelum memformulakan sediaan nanoemulsi, dilakukan optimasi formula nanoemulsi dilakukan dengan 12 formula dengan perbandingan yang berbeda.

Data hasil evaluasi optimasi formula berupa data $\mathrm{pH}$ dan persen transmittan nanoemulsi dari 12 perbandingan formula dapat dilihat di tabel 2.

Pada tabel 2 menunjukkan hasil evaluasi optimasi 12 formula nanoemulsi dengan berbagai perbandingan minyak pembawa MCT oil, surfaktan dan kosurfaktan, dari hasil optimasi didapat 5 formula dengan hasil evaluasi yang sesuai yaitu evaluasi $\mathrm{pH}$ dan $\% \mathrm{~T}$, Formula tersebut yaitu pada F1 dengan perbandingan $M C T$ Oil, Cremophor $\mathrm{RH}$ 40, dan PEG 400 (1:7:2) dengan hasil $\mathrm{pH}$ 5,7 dan $\% \mathrm{~T} 92 \%$, F8 dan F9 dengan perbandingan $M C T$ oil, Cremophor $\mathrm{RH}$ 40 Etanol (1:8:1) hasil pH 5,4 \% 97,3\% dan (1:6:1) Hasil $\mathrm{pH}$ dan \% $\mathrm{T}$ berturut turut 5.5 dan $97,5 \%$. Sedangkan pada F10 dan F12 dengan perbandingan MCT Oil, Tween 80, dan etanol (1:7:2) dengan $\mathrm{pH}$ 4,1 dan \% T 97.3\% lalu pada F12 pada perbandingan (1:6:1) hasil $\mathrm{pH} 4.1$ dan $\% \mathrm{~T}$ 98.7\%. Dari semua hasil 5 formula tersebut $\mathrm{pH}$ sediaan masih sesuai dengan $\mathrm{pH}$ kulit yaitu antara 4-6, sehingga aman digunakan dan tidak menyebabkan iritasi pada kulit, sedangkan untuk parameter persen transmittan jika hasil persen transmitan sampel mendekati persen transmitan akuades yakni $100 \%$, maka sampel tersebut memiliki kejernihan atau transparansi yang mirip dengan air dan dapat dikatakan bahwa sediaan nanoemulsi telah memiliki ukuran globul yang sangat kecil. ${ }^{[2] .}$

Data hasil formula nanoemulsi yang telah ditambahkan ekstrak dengan hasil evaluasi persen transmittan (\%T) dan nilai $\mathrm{pH}$ dapat dilihat dari tabel 3 hasil formula nanoemulsi.

Data hasil karakteristik nanoemulsi berupa organoleptis, ukuran partikel, indeks polidispersibilitas, dan $\mathrm{pH}$ dari formula terbaik yaitu pada 
formula 12 dengan perbandingan $M C T$ oil : Tween 80 : Etanol (1:6:1) dapat dilihat di tabel 4 Karakteristik fisik.

Pada tabel 3 didapatkan hasil formula terbaik dari hasil nanoemulsi yang kemudian ditambahkan kombinasi ekstrak bengkoang dan bunga mawar (1:3) ke dalam sediaan, dari ke lima sediaan tersebut hanya terdapat dua formula yang mendapatkan hasil evaluasi yang sesuai yaitu F9 dan F12 dimana keduanya memiliki perbandingan yang sama yaitu 1:6:1 namun dengan surfaktan dan kosurfaktan yang berbeda. Hasil $\mathrm{pH}$ pada F9 dengan perbandingan MCT Oil, Crempohor $R H 40$ dan Etanol (1:6:1) yaitu 5,5 sedangkan \% T menunjukkan $88 \%$. Dan kemudian formula terbaik yang selanjutnya yaitu pada F12 dengan perbandingan MCT oil, Tween 80, dan Etanol (1:6:1) dengan $\mathrm{pH} 4.1$ dan $\% \mathrm{~T}$ 90\%. Pada tabel 4 didapatkan hasil satu formula yaitu pada F12 dengan perbandingan MCT oil : Tween 80 : Etanol (1:6:1) yang telah memenuhi karakteristik fisik sediaan nanoemulsi yang baik dan sesuai dengan parameter yang ada, seperti hasil organoleptis warna kuning muda, dengan kejernihan yang jernih, memiliki bau khas, sedangkan homogenitas yang hasilnya homogen dilanjutkan untuk dilakukan pengukuran ukuran partikel dan indeks polidispersitas dengan masing-masing hasil yaitu $67,86 \mathrm{~nm}$, indeks polidispersibilitas 0,561 . Dilihat dari hasil ukuran partikel yang ada telah memasuki rentang yaitu 50$500 \mathrm{~nm}$ dan sedangkan untuk indeks polidispersibilitas yang mengindikasikan keseragaman ukuran droplet. Nilai polidispersibilitas yang rendah menunjukkan ukuran droplet yang seragam hasil telah sesuai dengan teori yang ada yaitu $<1^{[8] \text {. }}$

Tabel 3 Hasil formula nanoemulsi

\begin{tabular}{cccc}
\hline Formula & Ekstrak & T(\%) & $\mathrm{pH}$ \\
\hline F1 & & 66,7 & 5.7 \\
F8 & & 72,8 & 5.5 \\
F9 & $1: 3$ & 88 & 5.5 \\
F10 & & 78 & 4.1 \\
F12 & & 90 & 4.1 \\
\hline
\end{tabular}

Keterangan :

1:3 = Perbandingan kombinasi ekstrak bunga mawar dan bengkoang

$\mathrm{T}=$ Transmittan

Tabel 4 Karakteristik fisik formula 12

\begin{tabular}{ccccccccc}
\hline \multirow{3}{*}{ Formula } & \multicolumn{5}{c}{ Organoleptis } & & \multicolumn{2}{c}{ PSA } \\
\cline { 2 - 3 } & Warna & Kejernihan & Bau & Homogenitas & & $\begin{array}{c}\text { Ukuran } \\
\text { Partikel }\end{array}$ & $\begin{array}{c}\text { Indeks } \\
\text { polidispersibilitas }\end{array}$ \\
\hline \multirow{2}{*}{ F12 } & $\begin{array}{c}\text { Kuning } \\
\text { Muda }\end{array}$ & Jernih & Khas & Homogen & 4.1 & $67,86 \mathrm{~nm}$ & 0,561 \\
\hline
\end{tabular}

Keterangan :

F12 = MCT oil $:$ Tween $80:$ Etanol (1:6:1) 


\section{KESIMPULAN}

Formula terbaik pada Formula 12 dengan perbandingan MCT oil, Tween 80 dan Etanol dengan perbandingan 1:6:1 dengan hasil karakteristik nanoemulsi Kejernihan jernih, warna kuning muda, bau khas, dan homogen. $\mathrm{pH} 4,1$, pada $\% \mathrm{~T}$ $90 \%$ dan dengan ukuran partikel 67,86nm, Indeks Polidispersibilitas 0,561 .

\section{DAFTAR PUSTAKA}

[1] Alamsyah, Andi Nur., 2005, Virgin Coconut Oil Minyak Penakluk Aneka Penyakit, Penerbit Agro Media Pustaka, Jakarta

[2] Costa, J. A., Lucas, E. F., Queiros, Y. G. C., Mansur, C. R. E. 2012.Evaluation Of Nanoemulsions InThe Cleaning Of PolymericResins. Colloids SurfPhysicochem. Eng. Asp. 415.Pp. 112-118.

[3] Diba, Rovie Farah., Sedarnawati Yasni., Sri Yuliani. 2014. Nanoemulsifikasi Spontan Ekstrak Jinten Hitam dan Karakteristik Produk Enkapsulasinya. Jurnal Teknologi dan Industri Pangan. 25(2): 134-139.

[4] Gutierrez JM, Gonzalez C, Maestro A, Sole I, Pey CM, Nolla J. 2008.
Nanoemulsions: new applications and optimization of their preparation. Current Opinion in Colloid \& Interface Science. 13(4): 245-251.

[5] Lukitaningsih, E., Bahi, M., Holzgrabe, U. 2013. Tyrosinase Inhibition Type of Isolated Compounds Obtained from Pachyrhizus erosus. Aceh Int. J. Sci. Technol. 2 (3): 98-102.

[6] Makadia, H., Bhat, A., Parmar, R.,Paun, J., Tank, H. 2013. Selfnanoemulsifying Drug Delivery System (SNEDDS): Future Aspects, Asian J Pharm Res, 3(1):21-27.

[7] Rowe, R.C., Sheskey, P.J., and Quinn, M.E. 2009. Handbook of Pharmaceutical Excipients Sixth Edition. Pharmaceutical Press. London.

[8] Shakeel., et all.2008. Design Development and Evaluation of Novel Nanoemulsion Formulations for Transdermal Potential of Celexocib. Acta Pharmaceutica, 57:315-332.

[9] Yulianingsih, D. Amiarsih, R. Tahir dan Sabari S.D. 2006. Seleksi Jenis Bunga untuk Produksi Mutu Minyak Mawar. Jurnal Hortikultura 16 (4) : $345-348$. 